\title{
Waste Management by Utilization of Tire Rubber Aggregate in Concrete
}

\author{
Sourav Dey*, Mukesh Pandey** \\ *(M.tech Student Department of Civil Engineering, ITM University, Gwalior M.P \\ Email: dey.sourav66@gmail.com) \\ ** (Professor and Head Department of Civil Engineering, ITM University, Gwalior M.P \\ Email: HODcivil@itmuniversity.ac.in)
}

\begin{abstract}
The improvement of automobile Industry has associated with growth in predominant wastage components like that waste tire. The non-degradable the rubber and consequential dumping difficulty have to lead to critical problems of the environment to the present day. In order to solve the difficulty advance lot of resolutions procedure has been done. The problem has been solved expanding the waste element in concrete. Cement and aggregate which are the most significant materials in the construction industry. We can take necessary thought step to resolve the environment and to reduce the natural aggregate by using as a substitute material like unused tire rubber. The goal of this experiment to find out the waste rubber aggregate as some replacement in the normal aggregate. The M20 grade mix design in concrete have used in this experiment. The test is varying percentage of rubber aggregate from $10 \%, 15 \%$, and $20 \%$ with normal aggregate.
\end{abstract}

Keywords - Compressive strength, Flexural strength, Unit Weight, Rubber aggregate, Workability.

\section{INTRODUCTION}

Accumulations of unused tires have grown to be a countrywide trouble in unique nations around the world. In the USA more than 2.five billion tires have become waste. In different countries, the in the appropriate deposition of these waste tires contribute in potential fire and health hazard. Scrap tires are combustible in nature once indicated they generate a huge amount of black smoke and thus pollutes the air. Melting tires generate huge amount oil that contaminates the soil and groundwater. In order to reutilize the unused tire as an aggregate in concrete several research have been done. The utilization of waste tires in concrete as a coarse aggregate not only reduces the manufacturing cost of concrete but also reduces the environmental problem like degradation soil, air. The worldwide overall previous experiences obtained that the rubber aggregate will be applied in construction as a filler. Rubber concrete is given better physical and mechanical properties. The tire is a combination of cross-linked particles of Sulphur and other chemical materials. The tier is a thermoset material and vulcanization is the procedure of combining rubber with other chemicals. Due to the vulcanization post-consumer tires becomes very stable and non-degradable under ambient situations. Accordingly, to the study of above research, there is massive demand for utilization of mainly wasted tires and recycled substance in concrete in an environment-friendly way. Hence construction of concrete should be considered as realistic and suitable area.

\section{LITERATURE REVIEW}

Some of the previous research works on used of rubber aggregate have discussed briefly below.

Mr. Chothe Onkar K $\mathbf{K}^{\mathbf{1}}$, Mr. V.S. Kadam $^{2}$, Patil Vikram ${ }^{3}$ \& Patil Pravin4 May 2016: [1] Waste management has most important due to the unused tire rubber waste is growing at a fast rate. Concrete has noticed as any other source of recycling the tire rubber waste that may be replaced using in normal aggregate. On this investigated, effects on concrete have observed through experimental results. In this experimental research by means of M20 grade concrete used as reference point. Waste rubber tire had used 5\%, $10 \%$ and $15 \%$ substitute in coarse aggregate. And also discover percent value gain and strength ratio.

J. Raj Prasad 1 , V.Anuradha ${ }^{2} \&$ N.V. Rahul $^{3}$ April 2016: [2] On this examination, a examine were allowable on the make use of recycled rubber aggregates as a few alternative for coarse aggregates in concrete production. Inside the first a part of this application, the history of the study and the limit of the problem were considered. The research has accepted out by performing test 
within the fresh materials to define their properties for the experiment. The samples have been created with percent substitutes via $10 \%, 20 \%$ and $30 \%$ of rubber aggregate in natural aggregate.

\section{K.Charan Kumar ${ }^{1}$ \& Dr. S.Siddi Raju ${ }^{2}$} 2013: [3] On this investigated that the use of rubber tire pieces partial alternative in coarse aggregate for concrete production. The research had performed through accomplishing test on the additional resources to define their characteristics and suitability. The concrete mix designs became prepared to use the DOE technique and a complete number of 8 mixes had been organized containing two concrete grades M15 and M25. The samples have been produced with the percentage of replacements of the coarse aggregate through $10 \%$ 25 and $50 \%$ of rubber aggregates. Additionally, a controller combination with no replacement of the coarse aggregates changed into produced to make a comparative analysis. The prepared concrete mold containing concrete cubes and cylinders. The lists of experiments performed that unit weight, compressive and splitting tensile strength.

Kotresh K.M ${ }^{1}$ \& Mesfin Getahun Belachew ${ }^{2}$ April 2014: [4] At present-day in the world a major management problem for discarding of tires. It is expected that each year 1.2 billion of the waste tire is manufactured universally. It is also expected that user tires are exported $11 \%$, conducted to landfill stockpiled or dumped illegally $27 \%$ and used for civil engineering plans only $4 \%$. Therefore efforts have taken to classify the possible use of waste tires in civil engineering plans. In this situation, this current experiment goal to investigate the ideal use of waste tire rubber as aggregate in concrete mixed. A total number of 24 cubes and 12 prisms are cast of M25 grade by exchanging $10 \%, 20 \%$ and 30 percent of tire aggregate with coarse aggregate and likened with regular M20 grade concrete.

\footnotetext{
Mohammed Islamuddin Faraz $^{1}$, Utkarsh Jain ${ }^{2}$, Ketan Jain ${ }^{3}$ \& Shailendra Singh4 April 2015: [5] This experimental mix design may be defined as the system of selecting suitable substances for construction of concrete and to control their comparative quantities with an impartial to create a concrete mix having the necessary, workability, and durability in as inexpensive approach as ideal. This intention of the experiment that the effect of a substitute by means of $5 \%$ and $10 \%$ rubber crumbs in Portland cement concrete and coarse aggregate.
}

Parveen11, Sachin Das ${ }^{2} \&$ Ankit Sharma ${ }^{3}$ March 2013: [6] Now a day's crumb rubber is the ideal material to be used in the natural concrete dispensation. The motto of this observation is achieved to use of rubber waste a few replacement of quality combination to create rubberize concrete in M30 grade blend layout. Waste crumb rubber has a few replacements of $0 \%, 5 \%, 10 \%, 15 \%$ and $20 \%$ in an extent of fine aggregate are cast and experiment for compressive, flexural, splitting tensile strength and stress- strain characteristics.

\subsection{Effects on compressive, flexural and splitting tensile Strength:}

Mr. Chothe Onkar okay, Mr. V.S. Kadam, Patil Vikram \& Patil Pravin have been observed that compressive strength turned into decrees $9.3 \%$, $20.18 \%$ and $40.67 \%$ with growing percentage of rubber aggregate of 5\%,10\% and $15 \%$ in concrete it additionally shows that flexural and tensile strength reductions with growth the percentage of rubber aggregate in concrete [1]. J.Raj Prasad, V.Anuradha, and N.V. Rahul were determined that after the increase in curing length then additionally increases compressive strength. The quantities of coated Rubber aggregate and Rubber aggregate growth in coarse aggregate simultaneously lowering the strength of concrete. But, whilst changing $20 \%$ of the coarse mixture with rubber aggregate then gives the equal strength of ordinary concrete strength. Rubber aggregate produced is good strength than coated rubber aggregate [2]. K.Charan Kumar\& Dr. S.Siddi Raju had received that the compressive strength is lowering for adding rubber aggregate of concrete and additionally lowering of splitting tensile strength. However, there was the lowest decrease in splitting tensile strength compared to the decrees in the compressive strength [3]. Kotresh K.M \& Mesfin Getahun Belachew had investigated that the compressive strength and flexural strength of rubberized concrete had been lowering increasing percent of rubber aggregate and the tire reprocessing plants need to supply property of rubber aggregates in $20-10 \mathrm{~mm}, 10-4.75 \mathrm{~mm}$ downsizes to be used as cement concrete aggregate for better strength [4]. Mohammed IslamuddinFaraz, Utkarsh Jain, Ketan Jain \& Shailendra Singh were observed that the compressive strength average value increasing through used cracker mill method and granular process for 7, 14 and 28 days became obtained as $4 \%, 5.47 \%$ and $6.34 \%$ and the compressive strength average value of reduction by used micro mill method for 7, 14 and 28 days become acquired as $6 \%, 10.16 \%$, and $7.04 \%$, correspondingly $0 \%$, $5 \%$ and $10 \%$ [5]. Parveen1, Sachin Das \& Ankit 
Sharma were investigated that after $20 \%$ sand has changed then splitting tensile strength is reducing $30 \%$ and additionally decreasing $69 \%$ flexural strength and $37 \%$ compressive strength. For large percent of crumb rubber, the compressive strength benefit rate had decreased than that of plain concrete. Although, those facts offer an initial advice of the strength loss by produced adapted concrete in examining with the conventional concrete of 30 mpa energy [6].

\subsection{Effect on workability:}

Workability of concrete decreases as per increasing the rubber aggregate. This experiment recommended that super plasticizer to add for maintain the workability [1]. In this experiment, the slump value of normal concrete is less than of CRA and RA concrete. This experiment shows that coated rubber aggregate and rubber aggregate gives high workability of concrete [2]. This investigation shows that the workability rubber aggregate of concrete is better than normal concrete that's results are $32,38,41$ and 49 in $\mathrm{mm}$ according to $0 \%, 10 \%$, $25 \%$ and $50 \%$ for M15 grade and 7, 14, 21 and 42 in $\mathrm{mm}$ according to $0 \%, 10 \%, 25 \%$ and $50 \%$ for M25 grade [3]. The workability is increased for adding of rubber crumb. The values of slumps of $0 \%, 5 \%$, and $10 \%$ are got as $33.33,36.33$ and $38.33 \mathrm{~mm}$, correspondingly [5]. The workability of the altered concrete growths around $1.08 \%$, with the use of 1 to $10 \%$ of crumb rubber. [6].

\subsection{Effect on Unit weight:}

Unit weight of concrete decreases with increasing rubber aggregate proportion in concrete. That suggests it show that lightweight concrete [1]. The paper shows that rubber aggregate is light unit weight concrete so it's encouraged that one of the possible application in the version of rooftop faces for protection and waterproofing. With suitable combined design a $20 \mathrm{~mm}$ thick version on roof top faces can be used with $4.75 \mathrm{~mm}$ down rubber aggregate [3]. Unit weight of concrete is the reduction for adding rubber crumbs. The values of unit weights of $0 \%, 5 \%$, and $10 \%$ are got as 8.6 , 8.3 and 8.1 in kg correspondingly [6].

\section{CONCLUSION}

The overall conclusions had obtained from research that the tire rubber material can be used as aggregate in concrete.

- While rubber mixture became used as an alternative of aggregates in concrete then investigated show that decreased compressive strength and flexural strength replacement with normal concrete.

- Increasing compressive strength by way of used cracker mill system and granular procedure.

- Lowest lower in splitting tensile strength in comparison to the decrease in the compressive strength.

- When rubber aggregate was used as a recycled aggregate in concrete then its show the increasing the workability than the ordinary aggregate.

- Unit weight of rubber aggregate display that its light weight concrete so it's loads encouraged that where related have a look at value is applicable, then price can be saved in order that there we can be used rubber aggregate in concrete, however, there is certain limit of rubber aggregate can used in concrete because it impact on strength.

- It's much endorsed that super plasticizer to add for hold the workability.

- Stress-Strain suggests that concrete while with a better percentage of crumb rubber aggregate is mixed then gives excessive toughness.

\section{REFERENCES}

[1] Mr. Chothe Onkar K ${ }^{1}$, Mr. V.S.Kadam². Patil Vikram", Patil Pravin4. "Effect Of Replacement Of Course Aggregate By Scrap Tire Rubber Experimental Study". International Research Journal of Engineering and Technology Volume: 03 Issue: 05 | May2016.

[2] J.Raj Prasad ${ }^{1}$, V.Anuradha ${ }^{2}$, N.V.Rahul ${ }^{3}$. "Partial Replacement of Natural Aggregates with Reclaimed Rubber in Cement Concrete". SSRG International Journal of Civil Engineering (SSRG-IJCE) Volume 3 Issue 4 April 2016.

[3] K.Charankumar'1, Dr. S. Siddi Raju2. "Re-Use of Waste Tire Rubber Pieces in the Production of Light Weight Concrete". International Journal of Science and Research (IJSR) Index Copernicus Value (2013): 6.14 | Impact Factor (2013): 4.438 .

[4] Kotresh K.M ${ }^{1}$, Mesfin Getahun Belachew ${ }^{2}$. "Study on Waste Tire Rubber as Concrete Aggregates". International Journal of Scientific Engineering and Technology April 2014.

[5] Mohammed Islamuddin Faraz ${ }^{1}$, Utkarsh Jain ${ }^{2}$, Ketan Jain ${ }^{3}$, Shailendra Singh4. "Effect of Crumb Rubber Material on Concrete Mix". SSRG International Journal of Civil Engineering (SSRG-IJCE) - Volume 2 Issue 4 April 2015.

[6] Parveen ${ }^{1}$, Sachin Dass², Ankit Sharma ${ }^{3}$. "Rubberized Concrete: Needs of Good 
Environment". International Journal of Emerging Technology and Advanced Engineering Volume 3, Issue 3, March 2013.

[7] Prof. Warudkar A.A and Mr. Valekar N. S. "A Technical and Economic Assessment of Replacement of Coarse Aggregate By Waste Tire Rubber In Construction". Dept. of Civil Engineering, ICER, Wagholi. Pune, India. International Journal of Engineering Research and General Science Volume 3, Issue 3, MayJune, $2015 \quad$ ISSN 2091-2730.

Abhijit.icoer@gmail.com navanathvalekar@gmail.com 